\title{
MENINGKATKAN KEMAMPUAN KOGNITIF MELALUI MODIFIKASI PEMBELAJARAN SENTRA DI RA NURUL IDA KECAMATAN GEBANG KABUPATEN LANGKAT
}

\author{
Supiyah Erwani \\ Surel:Ranihidayat72@gmail.com
}

\begin{abstract}
Abstrak
Kemampuan dasar yang dapat dikembangkan pada anak salah satunya adalah kemampuan kognitif, karena kemampuan kognitif anak di RA Nurul Ida Langkat masih sangat rendah. Tujuan peneliatian adalah untuk meningkatkan kemampuan kognitif melalui modifikasi pembelajaran sentra di RA Nurul Ida Langkat. Prosedur penelitian ini adalah penelitian tindakan kelas, yang melalui beberapa tahapan yaitu perencanaan, pelaksanaan, pengamatan, serta refleksi. Penelitian yang dilakukan di RA Nurul Ida ini menggunakan PTK dengan melihat sampel dari kelompok B di RA Nurul Ida, Tekhnik penggumpulan data dilakukan dengan cara observasi, Tanya jawab, diskusi serta dokumentasi dengan menggunakan tekhnik analisis deskritif. Teknik Analisis data dengan meneliti setiap aspek kegiataan penelitian pada waktu dilaksanakan penelitian serta dianalisa secara baik, Hasil penelitian bahwa ada peningkatan kemampuan kognitif anak melalui metode pembelajaran sentra di RA Nurul Ida dari kondisi awal yang hanya 3 anak (21\%) meningkat di siklus pertama menjadi 6 orang anak (42\%) dan di siklus yang kedua mencapai 12 anak (85\%).Maka dapat disimpulkan kemampuan kognitif anak dapat meningkat melalui medifikasi pembalajaran sentra di RA Nurul Ida langkat.
\end{abstract}

Kata kunci: PTK, Kognitif, Pembelajaran sentra, siswa RA

\section{PENDAHULUAN}

Anak-anak memiliki kemampuan dasar yang dapat dikembangkan, salah satu kemampuan dasar yang dapat dikembangkan pada anak usia dini adalah kemampuan kognitif. Kemampuan kognitif adalah suatu proses berpikir, yaitu kemampuan individu menilai dan menghubungkan suatu kejadian atau peristiwa ( yuliana: 2005). Jadi kemampuan kognitif sangat penting untuk perkembangan anak, mengingat begitu kompleknya perkembangan yang dihadapi oleh anakanak, maksudnya bahwa kemampuan berpikir dan daya nalar anak dipengaruhi oleh kemampuan menggunakan bahasa yang menjelaskan berbagai konsep, ide, maupun hubungan-hubungan yang bisa dimanipulasi saat berpikir dan bernalar.

Kemampuan kognitif sangatlah berguna untuk anak, dengan kemampuan kognitif yang baik seorang anak dapat berinteraksi dengan lingkunganya dengan baik, karena dia mampu mengembangkan kemampuan berpikirnya untuk mempertahankan hidupnya dalam mengatasi masalah yang terjadi di dalam lingkungan sekitarnya.Kemampuan kognitif juga bermanfaat untuk meningkatkan

RA Nurul Ida Langkat Indah

ISBN: 978-602-50622-0-9 
kemampuan berbahasa anak, karena dengan daya nalar yang tinggi maka seorang anak mampu memahami dan mengerti, serta mentraformasikan bahasa dengan baik. Dengan inteligensi yang tinggi juga mampu membangun emosi yang positif, karena dengan kecerdasan emosi seorang anak dapat mengendalikan diri sehingga tidak terjerumus ke dalam tindakan-tindakan bodoh yang merugikan dirinya maupun orang lain.

Banyak sekali aspek-aspek yang dikembangkan dalam kemampuan kognitif, karena perkembangan kemampuan dasar anak antara yang satu dengan yang lain saling berkaitan dan tidak bisa dilepaskan begitu saja. Salah satu upaya untuk menigkatkan kemampuan kognitif dapat dilakukan dengan proses pembelajaran, pembelajaran yang sesuai dengan usia anak usia dini adalah belajar sambil bermain, karena dalam bermain banyak sekali hal-hal yang didapat oleh anak usia dini, maka untuk dapat memperoleh hasil pembelajaran yang baik diperukana adanya modifikasi pembelajaran.

Proses pembelajaran merupakan suatu proses yang mengandung serangkaian perbuatan guru dan siswa atau hubungan timbal balik yang berlangsung dalam situasi edukatif untuk mencapai tujuan pembelajaran (Risman:2012). Guru sangatlah berperan dalam proses pembelajaran, untuk menopang proses pembelajaran berlansung dengan baik. Melihat kondisi tenaga pendidik di RA Nurul Ida yang yang belum maksimal mengembangkan kemampuan dirinya menjadi guru yang berkompeten, yang belum dapat memahami, merancang dan mengkondisikan model-model pembelajaran dengan baik, salah satunya pembelajaran sentra.

Pembelajaran sentra adalah salah satu dari beberapa model pembelajaran di RA yang dapat dilaksanakan untuk meningkatkan kemampuan dasar anak, khususnya kognitif, model pembelajaran sentra dapat kita modifikasikan agar lebih menarik, dimana anak dan guru berada dalam satu lingkaran agar tidak ada batasan antara keduanya sehingga anak belajar dengan nyaman dan gembira (happy learning), yang dapat kita modifikasikan dengan lingkungan yang ada di sekitar kita, modifikasi sendiri berasal dari bahasa inggris "modification" (Jhon dan hasan shadly: 1992), perubahan, maka mengingat dan melihat kompleknya pembelajaran sentra. Maka tidak semua lembaga pendidikan anak usia dini dapat melakukan secara sempurna, apalagi lembaga-lembaga pendidikan yang ada di pedesaan karena itu perlu dilakukan modifikasi terhadap pembelajaran sentra yang akan dilaksanakan di lembaga-lembaga pendidikan di pedesaan.

Realita yang dihadapi di lapangan tidak seperti yang direncanakan, tidak terkecuali proses pembejaran sentra yang terjadi di RA Nurul Ida, kemampuan kognitif santri RA Nurul Ida yang masih rendah dalam mengeksplorasi kemampuannya dengan menggunakan lingkungan di sekitarnya dalam pijakan main di dalam modifikasi pembelajaran sentra, kurangnya kemampuan guru RA Nurul Ida dalam mengelola dan memodifikasi pembelajaran sentra dengan menggunakan lingkungan main, menjadikan belum terlaksananya proses 
pembelajaran dengan menggunakan modifikasi pembelajaran sentra, serta pemanfaatan model pembelajaran sentra yang dimodifikasikan belum dapat dilaksanakan di RA Nurul Ida yang berguna untuk meningkatkan kemampuan kognitif santri RA Nurul Ida.

Berdasarkan latar belakang di atas dan melihat kondisi di RA Nurul Ida serta hasil observasi yang dilakukan belum menunjukan hasil yang diharapkan. Maka peneliti mencoba untuk melakukan upaya meningkatkan kemampuan kognitif dengan modifikasi pembelajaran sentra secara seadaanya di RA Nurul Ida Gebang, kabupaten Langkat.

Metode yang digunakan di penelitian PTK ini adalah dengan penerapan modifikasi model pembelajaran sentra, yaitu berupa pendekatan pembelajar yang dalam proses pembelajarannya dilakukan di dalam lingkaran circle time dengan sentra bermain ditambahkan atau dimodifikasikan dengan lingkaran adalah dimana guru duduk bersama serta anak - anak dengan posisi melingkar untuk memberi pijakan (arahan) yang dapat menjadi fasilitator bagi siswa sebelum dan sesudah bermain, untuk mengembangkan seluruh potensi dasar anak khususnya kemampuan kognitif dalam berbagai aspek perkembangan secara seimbang. Dengan demikian melalui pembelajaran ini diharapan pengembangan kemampuan kognitif di kelompok B pada RA Nurul Ida Kecamatan Gebang dapat meningkat dan lebih baik dari sebelumnya. Tujuan penelitian iniadalah untuk meningkatkan kemampuan kognitif anak dengan modifikasi serta mengetahui pembelajaran sentra pembelajaran sentra di RA Nurul Ida Langkat Indah Kecamatan Gebang Kabupaten Langkat .

Desain Penelitian

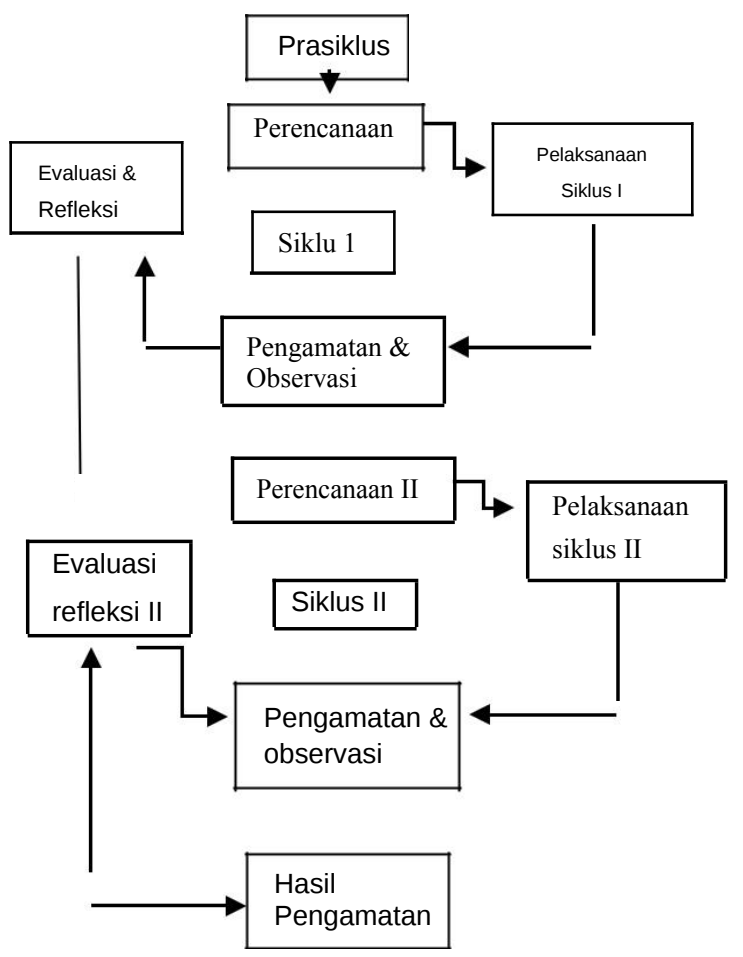




\section{HASIL PENELITIAN DAN PEMBAHASAN}

\section{Siklus I}

Untuk mengetahui kondisi awal, maka peneliti mengadakan observasi yang bekerjasama dengan guru lain. Kondisi yang terjadi pada saat ini menujukkan kemampuan kognitif anak masih rendah. Hal ini disebabkan kurangnya minat anak untuk mengeksplor lingkungan belajar yang ada di sekitarnya, sehingga anak belum mengunakan intelegensinya dengan maksimal, kurangnya kereatifitas guru dalam mengelola model-model pembelajaran yang ada dengan kondisi sekolah yang belum bisa menyediakan fasilitas sekolah yang memadai, maka peneliti melakukan tindakan kelas. Bertujuan untuk mengetahui strategi pembelajaran siklus pertama.

Berikut ini hasil siklus I

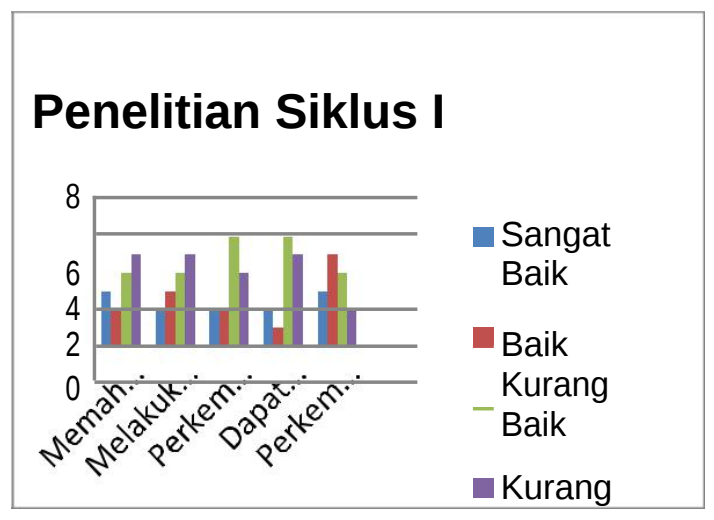

Grafik. Siklus I

Hasil observasi setelah mengadakan siklus I pada tabel grafik di atas, menunjukan kondisi pembelajaran setelah mengadakan penelitian yaitu anak yang memahami penjelasan guru 5 anak (35\%), melakukan kegiatan sesuai arahan guru 5 (35\%), perkembangan kemampuan kognitif dengan mengunakan model pembelajaran sentra 4 anak (29\%), dapat melakukan model pembelajaran 3 (21\%), dan dapat menggunakan kemampuan kognitifnya dengan menggunakan modifikasi pembelajaran sentra yang seadanya 8 (57\%), Dari kondisi yang terlihat di atas menujukan bahwa kemampuan kognitif anak sudah mulai meningkat walaupun belum maksimal. 


\section{Siklus II}

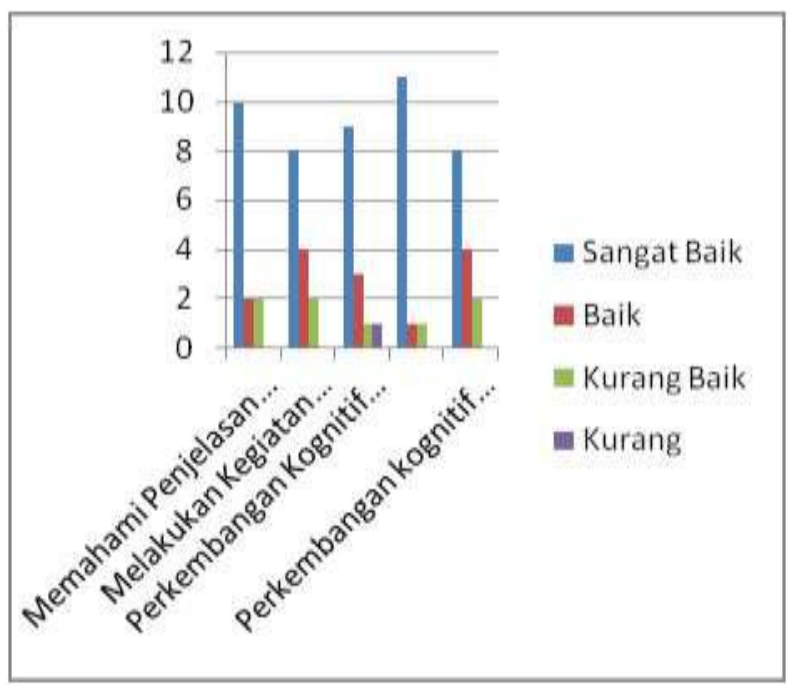

Grafik Siklus II

Hasil observasi dan evaluasi penelitian pada tabel dan grafik di atas, menunjukan kondisi pembelajaran pada siklus II yaitu anak yang memahami penjelasan guru, melakukan kegiataan pada sentra-sentra yang ada, perkembangan kognitif anak dengan modifikasi pembelajaran sentra, dapat melakukan kegiataan sesuai dangan pijakan, dapat melakukan kegiataan dalam sentra yang seadaanya. Hal ini menunjukan kemampuan kognitif anak sudah meningkat sesuai hasil yang diinginkan dengan menggunakan modifikasi pembelajaran sentra.

Setelah memodifikasi pembelajaran sentra dengan linkungan main yang seadaanya, dengan memberikan pijakan pada lingkungan main yang seadanya, sebahagian besar anak telah dapat memanfaatkan lingkunganya main dengan baik.

Meningkatkan kemampuan kognitif anak dengan disertai oleh kompertensi guru yang mampu melakukan perbaikan-perbaikan dalam proses pembelajaran serta mau merefleksi pelaksanaan kegiataan belajar mengajar, Peneliti memberikan motivasi yang lebih kepada anak yang tidak berminat dalam mencoba kegiataan pada sentra-sentra yang ada.

\section{Pembahasan}

Proses penelitian dari siklus pertama dan siklus kedua terlaksana dengan baik. Perkembangan kemampuan kognitif anak meningkat. Hal ini terlihat dari kemampuan anak mengeksplorasikan lingkungan mainnya lebih baik dari sebelum mengadakan tindakan. Guru juga lebih dapat melakukan inovasi, variasi serta memodifikasi model pembelajaran dengan lebih optimal. 
Hal ini terlihat dari sebelum mengadakan penelitian rata-rata kemampuan anak, siklus pertama naik menjadi ,dan siklus kedua menjadi. Dengan demikian dapatlah dinyatakan bahwa PTK yang dilakukan dapat meningkatkan kemampuan kognitif anak melalui modifikasi pembelajaran sentra di RA Nurul Ida Langkat.

Hasil observasi kognitif anak melalui modifikasi pembelajaran sentra pada pra siklus sampai siklus ketiga dapat dilihat pada Grafik berikut ini.

\section{Penelitian Kondisi Awal - Siklus II}

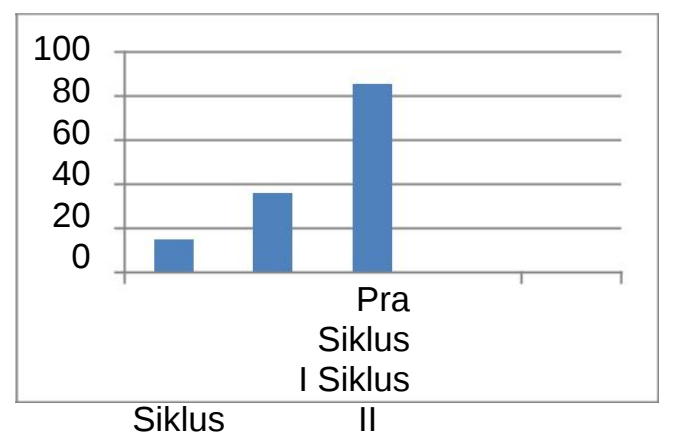

Grafik Kondisi awal-Siklus II

\section{SIMPULAN}

Berdasarkan hasil penelitian tindakan dan kolaborasi yang dilakukan selama dua siklus dapatlah disimpulkan bahwa: Modifikasi pembelajaran sentra dapat meningkatkan kemampuan kognitif pada anak RA Nurul Ida kelompok B Langkat, yang dapat merangsang kemampuan anak dengan mengeksplorasi alam disekitar mereka, melihat kondisi RA yang sangat kompleks dengan lingkungan main yang kurang mendukung maka pembelajaran sentra dilakukan dengan seadanya.

\section{DAFTAR RUJUKAN}

Aisyah, Siti. Pembelajaran Terpadu. Jakarta: Universitas Terbuka. 2010

Arikunto, Suharsimi, Dkk. Penelitian Tindakan Kelas Jakarta: Bumi Aksara. 2007

Djamarah, Syaiful Bahri, Aswin Zain. Strategi Mengajar. Jakarta: Rhineke Cipta. 2011

Drektorat Jendral Pendidikan Islam. Kurikulum RA. Jakarta: Kementrian Agama. 2011

Echols, M. Jhon. Hasan Shadly. Kamus Inggris - Indonesia. Jakarta Gramedia Pustaka Utama. 1982.

Ikhsan,Waseso, dkk. Evaluasi pembelajaran TK. Jakarta: Universitas Terbuka. 2007. 
Kunandar, ,Langkah Mudah Penelitian Tindakan Kelas. Jakarta: Rajawali Pers.2011

Masitoh, dkk. Strategi Pembelajaran TK. Jakarta: Universitas Terbuka. 2010 Poerwadarminta W.J.S Poerwadarminta. KAMUS Umum Bahasa Indonesia. Jakarta. Balai Pustaka.1985

Rusman. Model-model Pembelajaran. Jakarta: PT Raja Grafindo.2012.

Setiawan, Denny, dkk, Analisis Kegiatan Pengembangan Pendidikan Anak Usia Dini Jakarta Universitas Terbuka. 2010.

Syafarudin, dkk. Profesi Keguruan dan Pendalaman Materi. Sumatera Utara: IAIN. 2013.

Wahyono, Joko. Cara Ampuh merebut Hati Murid.Jakarta: Erlangga.2012.

Walter,Doyle Stanles. Berpikir Sebagai Pemenang.: Jakarta: Pustaka Tangga.1991.

Yuliani, Nuraini. Metode Pengembangan Kognitif.Jakarta: Universitas Terbuka.2005.

Http//www.yabunayya.com/2013/05/ Metode pembelajaran Sentra.html Http/Abazati art/Blong Sport com/2012/10/Definisi Afktif, kognitif, dan psikomotorik. 
ISBN: 978-602-50622-0-9 